\title{
EVALUATION OF THE COMPLICATIONS OF SURGICAL TREATMENT OF FRACTURES OF THE PROXIMAL EXTREMITY OF THE HUMERUS USING A LOCKING PLATE
}

Alberto Naoki Miyazaki', José Renato Depari Estelles², Marcelo Fregoneze ${ }^{3}$, Pedro Doneux Santos ${ }^{4}$, Luciana Andrade da Silva ${ }^{4}$, Guilherme do Val Sella ${ }^{4}$, Fábio Eduardo Ishioka ${ }^{5}$, João Polydoro Rosa ${ }^{5}$, Sergio Luiz Checchia ${ }^{6}$

\section{ABSTRACT}

Objective: To evaluate the complications from surgical treatment using a locking plate among patients with fractures of the proximal extremity of the humerus. Methods: Between July 2004 and December 2009, 56 patients with fractures of the proximal extremity of the humerus were treated using the PHILOS ${ }^{\circledR}$ plate. There were 19 male patients and 37 female patients, with a mean age of 62 years (range: 30 to 92 years). All the cases had a mean postoperative followup period of 12 months. Thirteen fractures were classified as presenting in two parts, 28 as three, eight as four and seven as epiphyseal fractures. Results: Among the patients operated, 26 were considered to have achieved excellent results, twelve good, ten fair and eight poor, according to the UCLA score. Thirty complications occurred in 20 patients
(35.7\%), among which the most frequent complication was inadequate reduction of the fracture, which occurred in eight cases. Subacromial impact, caused by the plate, occurred in seven cases, while inadequate fixation occurred in six cases. Other complications such as pseudarthrosis, adhesive capsulitis, avascular necrosis, loss of varus reduction and infection were also seen. Conclusion: The functional results from treating fractures of the proximal extremity of the humerus using a locking plate depended on correct anatomical reduction of the fracture and stable fixation of the implant. Complications still occur frequently, particularly because of intraoperative technical difficulty, fracture severity and possible inexperience of the surgeon.

Keywords - Shoulder Fractures; Fracture Fixation, Internal; Bone Plates

\section{INTRODUCTION}

The frequency of fractures of the proximal extremity of the humerus has been increasing as the population ages. When these fractures occur in elderly patients, they are associated with osteoporosis ${ }^{(1)}$. Thus, choosing the treatment to use will depend not only on the type of fracture and the surgeon's experience, but also on the patient's bone quality, age and degree of activity ${ }^{(2)}$. Several fixation methods have been described in the literature for treating these fractures: percutaneous fixation with Kirschner wires, angled plates, tension bands, tie bands, intramedullary nails, T-shaped plates and, most recently, "locking plates"(3-8).

The aim in the constant evolution of synthesis materials has been to diminish the incidence of complications $^{(9)}$. Despite the diversity and technical evolution of fixation methods, a variety of complications continue to be reported, such as: pseudarthrosis, skewed

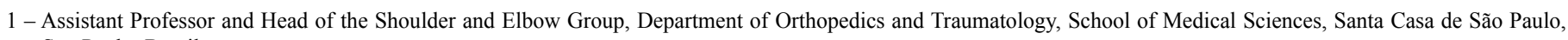
São Paulo, Brazil.

2 - Resident in the Department of Orthopedics and Traumatology, School of Medical Sciences, Santa Casa de São Paulo, São Paulo, Brazil.

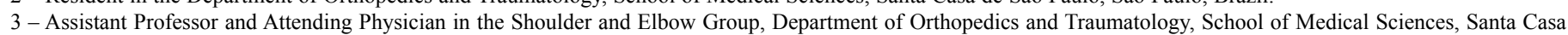
de São Paulo, São Paulo, Brazil.

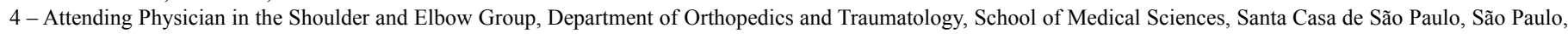
Brazil.

5 - Trainee in the Shoulder and Elbow Group, Department of Orthopedics and Traumatology, School of Medical Sciences, Santa Casa de São Paulo, São Paulo, Brazil.

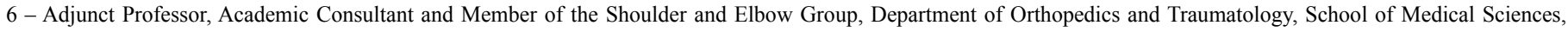
Santa Casa de São Paulo, São Paulo, Brazil.

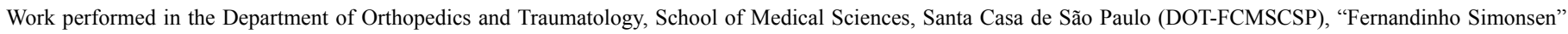
Wing, São Paulo, Brazil. Director: Prof. Dr. Osmar Avanzi.

Correspondence: R. Dr. Cesário Mota Jr. 112, Vila Buarque, 01221-020 São Paulo, SP. E-mail: ombro@ombro.med.br

Work received for publication: February 1, 2011; accepted for publication: March 8, 2012.

The authors declare that there was no conflict of interest in conducting this work 
consolidation, avascular necrosis, implant failure, adhesive capsulitis, infection, paralysis of the deltoid muscle, inadequate fixation of the plate, migration of the screws and subacromial impact caused by the implant $^{(4,7,9-14)}$. The development of "locking plates" for the proximal extremity of the humerus has brought a new perspective for treatment of fractures, especially for fractures in three or four parts, epiphyseal fractures in young patients and fractures in bones that have become fragile, for which there is greater technical difficulty in fixation $^{(13)}$. The theory of the mechanical advantage of "locking plates" is that sufficient stability is achieved without bone-plate contact, which would be necessary if conventional plates were used ${ }^{(15)}$. This stability is provided by means of locking screws, thereby leading to better results in bones that are porous ${ }^{(7)}$.

Currently, the Philos ${ }^{\circledR}$ plate (Proximal Humerus Internal Locked System) developed by the AO-ASIF group is one of the implants used for treating fractures of the proximal extremity of the humerus. It forms part of the latest generation of locking compression plates ${ }^{(10,14)}$.

Fankhauser et $a l^{(4)}$ and Duralde and Leddy ${ }^{(9)}$ showed their results from using "locking plates" for treating fractures of the proximal extremity of the humerus. They found complication rates of 20 to $30 \%$, and these complications included pseudarthrosis, inadequate reduction, infections, subacromial impact, nerve lesions and implant failure.

Complications from using "locking plates" may occur both in relation to the surgical technique (poor positioning of the plate, inappropriate screw size or quality of the reduction) and in relation to problems with the implant and fracture themselves (poor indication of osteosynthesis, pseudarthrosis and osteonecrosis of the humeral head) ${ }^{(13)}$.

The aim of the present study was to assess the complications from treatment among patients who underwent open reduction and internal fixation of fractures of the proximal extremity of the humerus, using the Philos ${ }^{\circledR}$ "locking plate".

\section{MATERIALS AND METHODS}

Between July 2004 and December 2009, the Shoulder and Elbow Group of the Department of Orthopedics and Traumatology, School of Medical Sciences of Santa Casa de São Paulo, operated on 57 patients with fractures of the proximal extremity of the humerus, with fixation using the Philos ${ }^{\circledR}$ locking plate.
One patient was excluded from the study because this individual was lost from the follow-up. Nineteen patients (34\%) were male and 37 (66\%) were female.

The inclusion criteria for this study were that the patients should be over 18 years of age, with acute fractures of the proximal extremity of the humerus that required surgical stabilization, and with a minimum postoperative follow-up of 12 months.

The following were exclusion criteria: fractures of the proximal extremity of the humerus in patients under the age of 18 years, fractures in bones presenting tumors, exposed fractures, fractures without displacement for which conservative treatment was chosen and fractures treated by means of partial replacement arthroplasty.

The patients' mean age was 62 years, with a range from 30 to 92 . The dominant side was affected in 31 patients $(55.3 \%)$. The mean number of days between the date of the fracture and the date of the surgery was seven days, with a range from zero to 20 days.

All the fractures of the proximal extremity of the humerus were classified in accordance with $\mathrm{Neer}^{(16)}$, as shown in Figure 1.

The patients were evaluated with regard to age, sex, dominance, length of time between the fracture and the surgery, type of fracture, surgical technique, time taken to achieve consolidation and any presence of complications.

All the patients underwent the operation in the deckchair position under general anesthesia and brachial plexus blockade. The bone fragments were dealt with by means of a deltopectoral route. After reduction of the fragments, the fracture was fixed provisionally using metal wires and/or suturing, the reduction was checked again by means of an image intensifier and the plate was placed in the anterolateral position of the proximal region of the humerus.

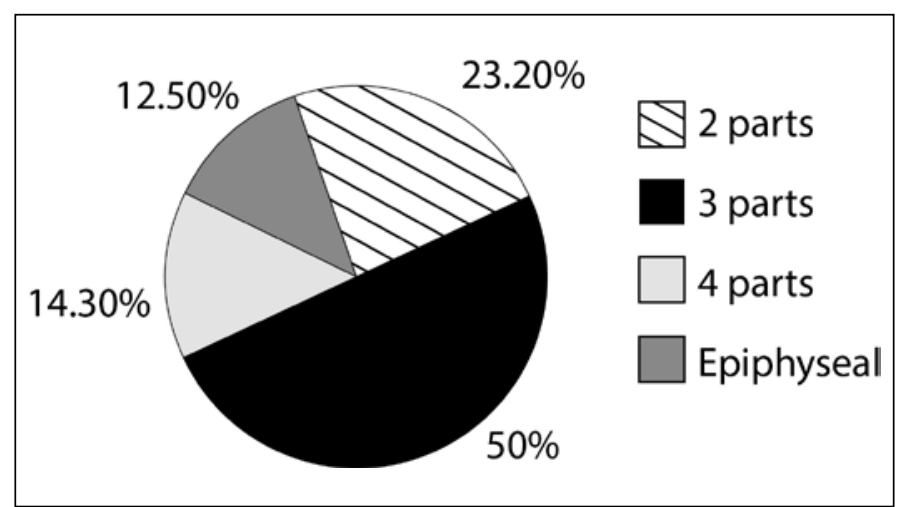

Figure 1 - Percentage distribution of types of fracture of the proximal extremity of the humerus. 
A guidewire was passed through the upper region of the plate and through the guide for this purpose, in order to check its height in relation to the greater tubercle. The number of screws placed in the humeral head ranged from four to seven (mean of 5.3). The lengths of the screws were checked using an image intensifier at maximum lateral and medial rotations. Using stitches of non-absorbable thread (number 5), the proximal region of the plate was fixed to the tendons of the supraspinatus, infraspinatus and subscapularis muscles in order to add stability to the fixation. The size of the Philos ${ }^{\circledR}$ plate used ranged from three to nine holes (mean of 3.2). A bone graft was used when the surgeon judged that this was necessary; this occurred in seven patients $(12.5 \%)$.

The operated shoulder was immobilized for at least four weeks. The patients underwent passive shoulder exercises between the second and sixth postoperative weeks, until there was radiographic evidence of consolidation. After consolidation of the fracture, exercises to gain active shoulder mobility were started.

Postoperative outpatient evaluations were performed after two, four, six, 12, 24 and 52 weeks. The patients were evaluated and classified using the University of California at Los Angeles (UCLA) score ${ }^{(17)}$ and radiographically regarding the position of fracture consolidation (anatomical or displaced) and the time taken to achieve consolidation.

The statistical assessment of the present study was done using the chi-square and Fisher exact tests. We used the significance level of 5\% (0.05) for applying the statistical tests, and differences were considered to be significant when $p<0.05$. This study was approved by the Research Ethics Committee. There were no conflicts of interest in the present study.

\section{RESULTS}

Among the 57 patients who were treated surgically using a locking plate, 56 were followed up as outpatients after the operation for at least 12 months. One patient did not return for outpatient follow-up. The mean UCLA score was 29.5 points, with a range from 12 to 35 points, and the results can be evaluated in Table 1 .

The mean elevation of the operated shoulder was $127^{\circ}$, with a range from 70 to $160^{\circ}$. The mean lateral rotation was $42^{\circ}$, with a range from 10 to $70^{\circ}$. The mean medial rotation was at the $\mathrm{L} 2$ level, with a range from $\mathrm{T} 5$ to $\mathrm{S} 2$.
Thirty complications occurred in 20 patients (35.7\%) and these are presented in Table 2. Eight patients $(40.0 \%)$ had more than one complication. The complications taking into account the type of fracture according to the Neer classification ${ }^{(16)}$ can be seen in Table 3 and Figure 2.

Among the eight cases of inadequate reduction of the fracture, two (25\%) were epiphyseal fractures, four $(50 \%)$ were fractures in three parts and two $(25 \%)$ were fractures in four parts. Among the inadequate reductions, six presented varus, one valgus and one anteversion of the humeral head. Inadequate reduction was the most frequent complication, with a statistically significant difference in occurrence between this complication and the others $(p<0.05)$.

Among the seven cases of complications from the subacromial plate caused by the plate, four occurred in three-part fractures, two in epiphyseal fractures and one in a two-part fracture $(\mathrm{p}>0.05)$.

Out of the six cases of inadequate fixation of the fracture, four had locking screws for the head that were too short (less than one centimeter from the joint surface) and two had screws that were too long. Inadequate fixation occurred in four cases of three-part fractures and in two epiphyseal fractures.

Table 1 - Evaluation of the results according to the UCLA score.

\begin{tabular}{c|c|c}
\hline Results & Number of patients & $\%$ \\
\hline Excellent & 26 & 46.4 \\
\hline Good & 12 & 21.4 \\
\hline Fair & 10 & 17.9 \\
\hline Poor & 8 & 14.3 \\
\hline Total & 56 & 100 \\
\hline
\end{tabular}

Fonte: Arquivos médicos da Irmandade Santa Casa de Misericórdia de São Paulo.

Table 2 - Complications relating to fixation of fractures in the proximal third of the humerus using Philos ${ }^{\circledR}$ plates.

\begin{tabular}{c|c|c}
\hline Complications & Cases & $\%$ \\
\hline Inadequate reduction & 8 & 26.7 \\
\hline Impact due to the plate & 7 & 23.3 \\
\hline Inadequate fixation & 6 & 20 \\
\hline Pseudarthrosis & 3 & 10 \\
\hline Adhesive capsulitis & 2 & 6.7 \\
\hline Avascular necrosis & 2 & 6.7 \\
\hline Loss of reduction in varus & 1 & 3.3 \\
\hline Infection & 1 & 3.3 \\
\hline Total & 30 & 100 \\
\hline
\end{tabular}

Table 3 - Complications according to the type of fracture, using the Neer classification.

\begin{tabular}{c|c|c|c}
\hline Type of fracture & Number of patients & Complications & $\%$ \\
\hline 2 parts & 13 & 3 & 23.1 \\
\hline 3 parts & 28 & 10 & 35.7 \\
\hline 4 parts & 8 & 3 & 37.5 \\
\hline Epiphyseal & 7 & 4 & 57.1 \\
\hline Total & 56 & 20 & 35.7 \\
\hline
\end{tabular}




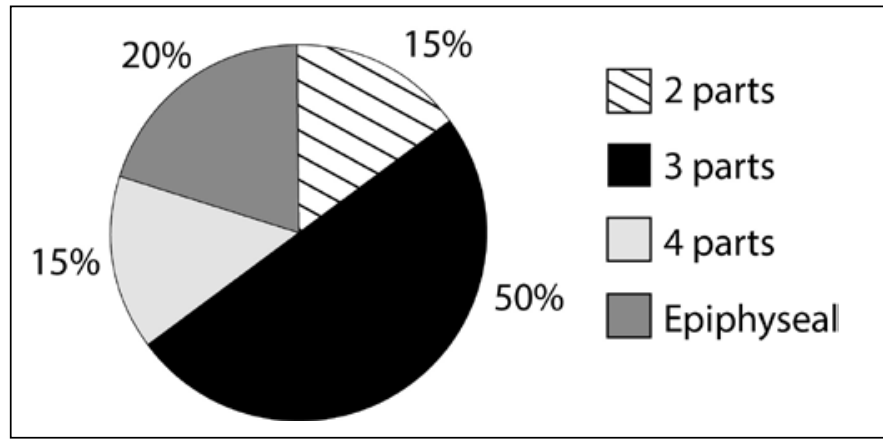

Figure 2 - Complications from surgical treatment in relation to the type of fracture.

There were three cases of pseudarthrosis: one patient with an epiphyseal fracture in association with a fracture of the greater tubercle and surgical neck that was poorly reduced, remaining in varus; one patient with a four-part fracture that was inadequately reduced and remained in varus; and one patient with an anatomical reduction and fixation of a three-part fracture but who evolved to pseudarthrosis.

Adhesive capsulitis occurred in two patients, with two and three-part fractures.

There were two cases of necrosis of the humeral head: one in a three-part fracture and the other in a four-part fracture.

One patient with a two-part fracture evolved with loss of the reduction in varus and there was one case of infection in a patient with a three-part fracture.

\section{DISCUSSION}

We had 30 complications in 20 patients (35.7\%). In the literature, we found complication rates ranging from 3.7 to $33.5 \%{ }^{(18,19)}$. In a multicenter prospective study conducted by Südkamp et $a l^{(19)}$, it was observed that $33.5 \%$ of the patients evolved with complications. Among the complications observed by those authors, the following were seen: migration of the screws, subacromial impact, pseudarthrosis, loss of reduction, avascular necrosis, neurological lesions, breakage of the implant, inadequate fixation and infection ${ }^{(19)}$. If we only take into account the patients who presented complications in our study, the mean UCLA score of 29.5 points falls to 22.6 . If we only take into account the patients without complications, the mean UCLA score rises to 33.4 points (ranging from 28 to 35 points). Patients with complications evolved with a mean elevation of $118^{\circ}$, while the others presented $132^{\circ}$; mean lateral rotation of $38.5^{\circ}$, versus $43.8^{\circ}$; and mean medial rotation at L3 level, versus L2.
Inadequate reduction of the fracture was the main complication found in our study, and was the only complication that was statistically significantly different among all of them. We had eight cases (14.3\%) of poor reduction, which were associated with three-part, four-part and epiphyseal fractures. This rate is in accordance with the literature, which shows rates ranging from 13.7 to $25 \%{ }^{(4,12,20)}$. We believe that this high rate is associated with difficulty in reducing the fracture and keeping it reduced until the plate is positioned and fixed to the bone. Koukakis et $a l^{(6)}$ considered that the greatest challenge in this surgery was to achieve anatomical reduction of the fracture, especially in three and four-part fractures. Duralde and Leddy ${ }^{(9)}$ affirmed that in relation to fractures impacted in varus, there is great surgical difficulty in achieving adequate reduction and maintaining this because of the lack of support for the medial region of the metaphysis.

It is known that correct reduction of the greater tubercle is also an important parameter for ensuring favorable results $^{(21)}$. Kettler et al $^{(22)}$ found a statistically significant difference in postoperative evolution between patients with correct reduction of the greater tubercle and those with displacement of the greater tubercle greater than five millimeters. In our study, there was one case $(1.7 \%)$ in which adequate reduction of the greater tubercle did not occur (Figure 3). Despite this, the patient evolved with consolidation of the fracture, shoulder elevation of 90 degrees, UCLA score of 30 points, absence of pain and satisfaction with the operation.

It is important to emphasize that the locking plate did not contribute towards reduction of the fracture: fixation of the implant should be done with the fractured already reduced, and this is one of the biggest difficulties with treatments using this type of implant ${ }^{(9)}$. Several thin metal wires are placed in order to maintain the reduction while the plate is being positioned. Since the plate is positioned laterally to the bone, there is often great difficulty in maintaining this. In our sample, six cases continued to present varus deviation (Figure 3), one case presented inadequate reduction in valgus and one case presented reduction of the humeral head with fixation in anteversion.

In the attempt to correct the varus deviation of a fracture, overcorrection may occur, thus resulting in reduction in valgus. This may occur due to lack of any anatomical parameter, because of comminution of the fracture. One patient in our study had a fracture fixed in valgus. 


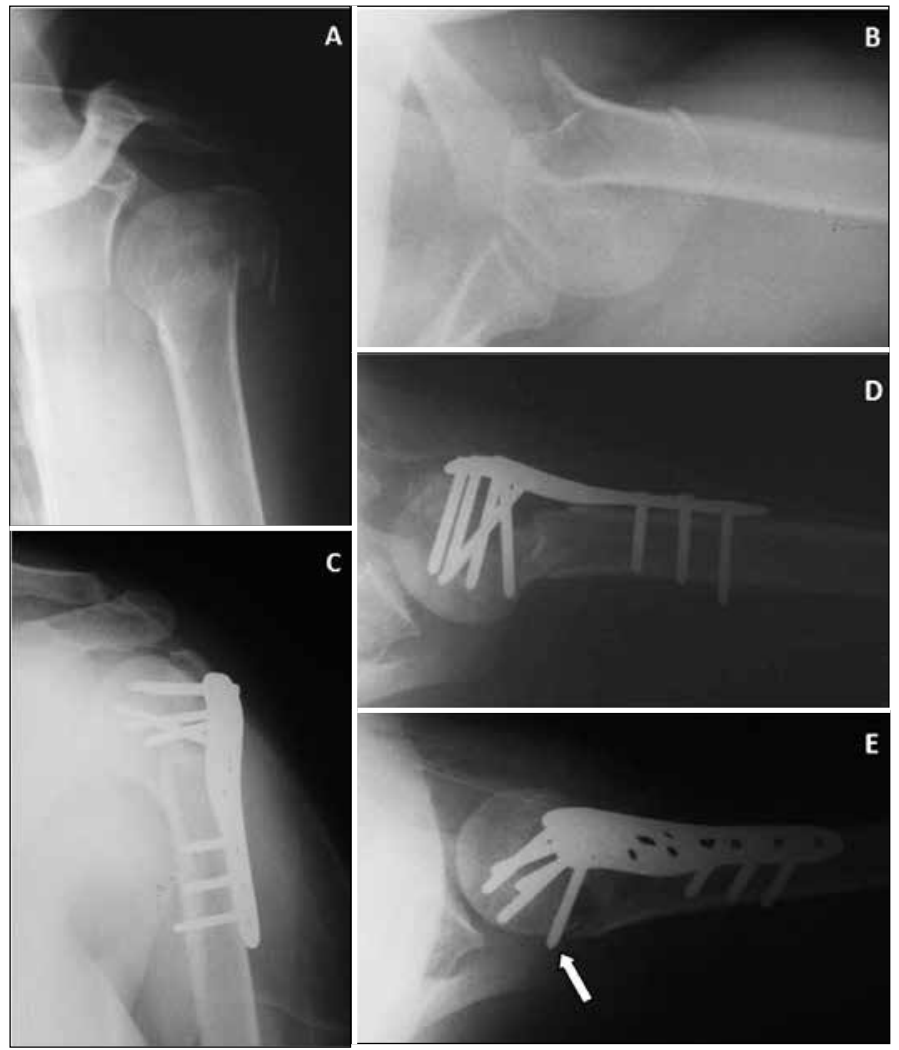

Figure 3 - Patient aged 79 years who suffered a fracture of the proximal extremity of the left humerus in three parts (surgical neck and greater tubercle), showing preoperative radiographic images (A) in anteroposterior position (B) in axillary lateral view. Immediate postoperative images showing $(C$ and $D)$ inadequate reduction of the fracture, which remained in varus of 110 degrees, with the greater tubercle not reduced, and (E) protrusion of the posterior screw (arrow).

Among the cases of inadequate reduction in varus, two cases evolved to pseudarthrosis. We believe that bone failure in the medial portion of the metaphysis may have contributed towards these complications. In these two cases, no grafts were used.

Gardner et al ${ }^{(23)}$ demonstrated recently that absence of mechanical support in the medial region of the proximal extremity of the humerus, which was caused when there was no cortical contact in the medial region of the metaphysis or in comminutive fractures, contributed towards loss of reduction in varus. Thus, placement of a bone graft in the medial region of the metaphysis is fundamentally important for avoiding loss of reduction ${ }^{(9)}$. Our usual procedure is to place a bone graft in the cavity between the humeral head and the metaphysis, where the bone failure is, and not necessarily in the medial region of the metaphysis. Moreover, we believe that suturing the tubercles to the plate has an important role in avoiding loosening of the plate. For good fixation, thereby avoiding loss of reduction and pseudarthrosis, another important factor is the position of the screws in the central, lower and posterior regions of the humeral head, where the trabecular density is greater ${ }^{(24,25)}$. It is important to emphasize that poor positioning of the humeral head does not allow correct positioning of the screws, given that the screws are placed at a fixed angle.

Pseudarthrosis occurred in $5.3 \%$ in our study, while in the literature the rates of pseudarthrosis have ranged from 3 to $5.5 \%^{(10,13,21)}$. In the only one of our three cases of pseudarthrosis in which the cause was not failure of the reduction, the patient was a 47-year-old woman who was a smoker and drinker. It is known that both alcohol consumption and smoking are risk factors for pseudarthrosis ${ }^{(26)}$. A few months after the operation, thus patient suffered a fracture of the proximal extremity of the humerus on the contralateral side, without displacement. She underwent conservative (non-surgical) treatment and also evolved with pseudarthrosis.

The second most frequent complication in our study was subacromial impact caused by the plate, which occurred in seven patients $(12.5 \%)$. In a review of the literature, we found rates of occurrence of subacromial impact ranging from zero to $10.3 \%{ }^{(4,6,12,27)}$. According to some authors, the plate should be positioned between five and eight millimeters from the apex of the greater tubercle; if not, a mechanical impact on the acromion might occur when the shoulder is raised ${ }^{(9,27,28)}$. In our study, we observed five cases of impact caused by placement of the plate in positions that were too high, i.e. less than five millimeters from the apex of the greater tubercle, and two cases of impact caused by placement of the plate too laterally (Figure 4). To avoid this complication, we are now placing the guidewire and the plate at positions that are lower than in the recommended technique. In all of our seven cases of impact, there were improvements in the state of pain and shoulder mobility after removal of the implant.

We had two cases in which the screw penetrated the glenohumeral joint. In one of them, a 59-year-old patient with a three-part fracture evolved with osteonecrosis of the humeral head. The rate at which screws are drilled into the joint has ranged from 14 to $16 \%$, and this may have been caused as much by collapse of the subchondral bone as by implant failure, screw migration, drilling with the bit into the joint surface or inadequate viewing with the image intensifier ${ }^{(19,29,30)}$. Thanasas et $a l^{(21)}$ stated that the commonest intraoperative error was to incorrectly choose the 


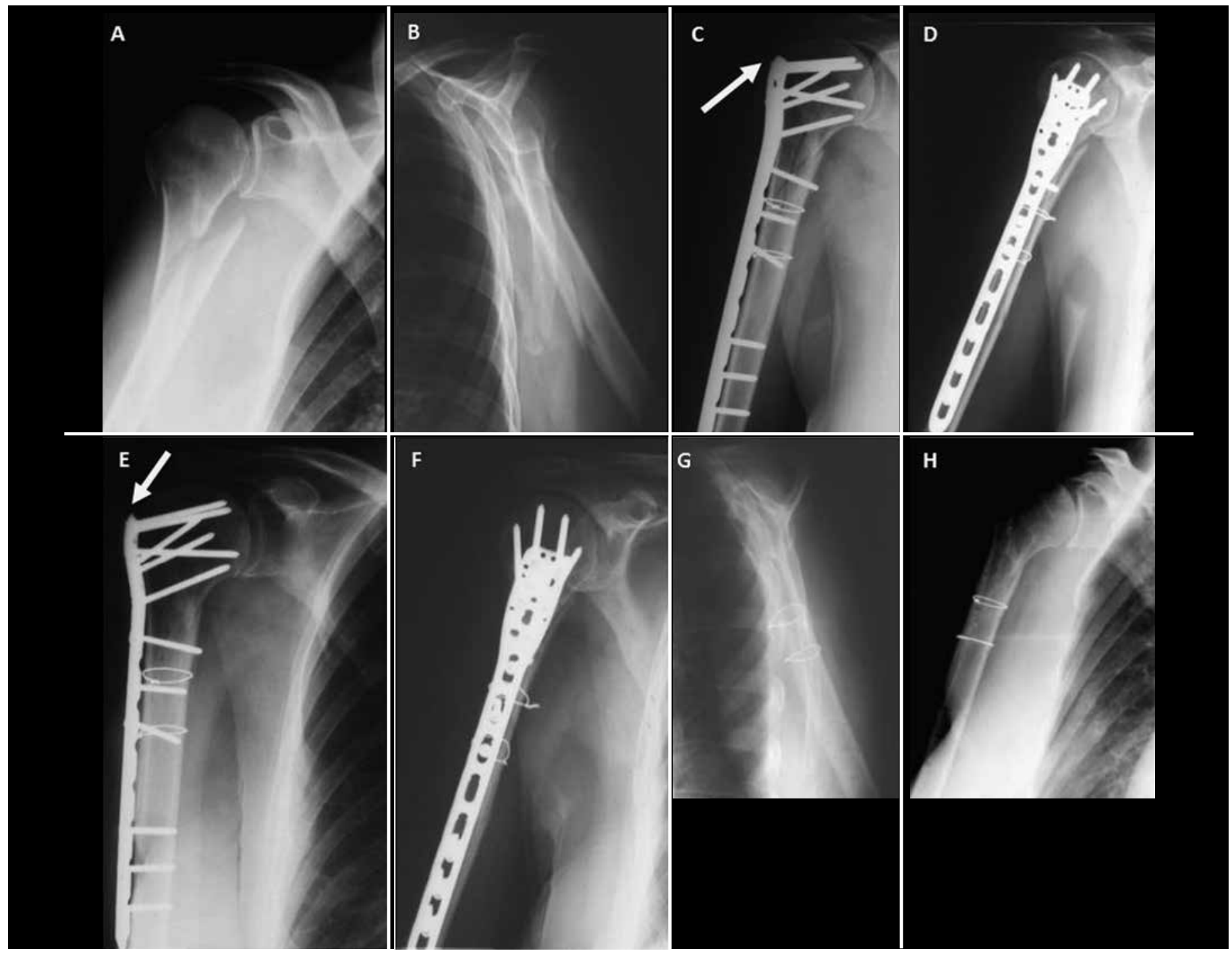

Figure 4 - Pre and postoperative radiographic images of the right shoulder of a 71-year-old patient who suffered a two-part fracture of the proximal extremity of the humerus with a metadiaphyseal line. (A) Preoperative corrected frontal view of the fracture. (B) Preoperative scapular lateral view. (C and D) Immediate postoperative views: note the white arrow showing the high position of the plate, very close to the upper margin of the greater tubercle. ( $E$ and F) Radiographic views one year after the surgery with the fracture already consolidated. ( $G$ and $H)$ Radiographs after removal of the plate, which led to improvement of the painful condition and a gain in mobility.

size of locking screw, which accounted for between 2 and $17.9 \%$ of these complications ${ }^{(14)}$. We had four cases $(7.1 \%)$ of short screws and two cases $(3.5 \%)$ of protruding screws (Figure 3). According to Duralde and Leddy ${ }^{(9)}$, the screws in the humeral head should be five to ten millimeters from the joint surface.

We tended to also tie off the tendons of the rotator cuff muscles at the plate with the aim of augmenting the fracture fixation in order to avoid postoperative loss of the reduction. Loss of the reduction occurred in one case $(1.7 \%)$ in our study.

Edwards et al ${ }^{(31)}$ demonstrated that in cases of comminutive fractures of the surgical neck, the biomechanical resistance of locking plates (in relation to both their angular and their torsional strength) was greater than that of locking intramedullary nails. No cases of breakage of the implant occurred in our study, whereas the rate of occurrence described in other studies was between 0.7 and $3 \% \%^{(4,10,21)}$. This was probably because in most cases in which the comminution was large, it was decided to place a bone graft together with fixation of the plate. A bone graft was placed in seven patients (12.5\%) and, among these, two evolved with complications. The first of these was in a case of a three-part fracture of the greater tubercle and surgical neck, and it evolved with signs of impact caused by the plate, due to high fixation. The second case consisted of a four-part fracture and evolved with avascular necrosis.

Few studies have specifically addressed the com- 
plications and technical difficulties of surgery for treating fractures of the proximal extremity of the humerus using a "locking plate". One of the weak points of the present study was that it was retrospective, without a control group.

It is important to emphasize that the functional results from fractures of the proximal extremity of the humerus are less dependent on the choice of implant; rather, they depend on correct anatomical reduction of the fracture and stable fixation of the implant ${ }^{(27)}$. It is believed that in elderly patients with osteoporosis and in cases of comminutive fractures, "locking plates" ensure greater stability of fixation and fewer risks of loss of reduction.

It has been noted that there is some difficulty in achieving adequate reduction of the fracture in association with good positioning of the plate on the bone, even taking into account the different fractures

\section{REFERENCES}

1. Papadopoulos P, Karataglis D, Stavridis SI, Petsatodis G, Christodoulou A Mid-term results of internal fixation of proximal humeral fractures with the Philos plate. Injury. 2009;(40):1292-6.

2. Iannotti JP, Ramsey ML, Williams GR Jr, Warner JJ. Nonprosthetic management of proximal humeral fractures. Instr Course Lect. 2004;(53):403-16.

3. Resch $\mathrm{H}$, Hubner $\mathrm{C}$, Schwaiger $\mathrm{R}$. Minimally invasive reduction and osteosynthesis of articular fractures of the humeral head. Injury. 2001;32(Suppl 1):SA25-32.

4. Fankhauser F, Boldin C, Schippinger G, Haunschmid C, Szyszkowitz R. A new locking plate for unstable fractures of the proximal humerus. Clin Orthop Relat Res. 2005;(430):176-81.

5. Lill H, Hepp P, Korner J, Kassi JP, Verheyden AP, Josten C, Duda GN. Proximal humeral fractures: how stiff should an implant be?: A comparative mechanical study with new implants in human specimens. Arch Orthop Trauma Surg. 2003;(123):74-81.

6. Koukakis A, Apostolou CD, Taneja T, Korres DS, Amini A. Fixation of proximal humerus fractures using the PHILOS plate: early experience. Clin Orthop Relat Res. 2006;(442):115-20.

7. Brunner F, Sommer C, Bahrs C, Heuwinkel R, Hafner C, Rillmann P, et al. Open reduction and internal fixation of proximal humerus fractures using a proximal humeral locked plate: a prospective multicenter analysis. J Orthop Trauma. 2009;(23):163-72.

8. Checchia SL, Doneux PS, Miyazaki AN, Fregonese M, Silva LA, Lobo AC, et al. Avaliação do tratamento cirúrgico da fratura em duas partes do colo cirúrgico do úmero com placa PFS 80. Rev Bras Ortop. 2004;39(10):555-67.

9. Duralde XA, Leddy LR. The results of ORIF of displaced unstable proximal humeral fractures using a locking plate. J Shoulder Elbow Surg. 2010;19(4):480-8.

10. Björkenheim JM, Pajarinen J, Savolainen V. Internal fixation of proximal humeral fractures with a locking compression plate. A retrospective evaluation of 72 pacients followed for a minimum of 1 year. Acta Orthop Scand. 2004;75(6):741-5.

11. Plecko M, Kraus A. Internal fixation of proximal humerus fractures using the locking proximal humerus plate. Operat Orthop Traumatol. 2005;(17):25-50.

12. Agudelo J, Schürmann M, Stahel P, Helwig P, Morgan SJ, Zechel W, et al. Analysis of efficacy and failure in proximal humerus fractures treated with locking plates. J Orthop Trauma. 2007;(21):676-81.

13. Clavert P, Adam P, Bevort A, Bonnomet F, Kempf JF. Pitfalls and complications with locking plate for proximal humerus fracture. J Shoulder Elbow Surg. 2010;(19):489-94.

14. Shahid R, Mushtaq A, Northover J, Maqsood M. Outcome of proximal humerus fractures treated by PHILOS plate internal fixation. Experience of a district general hospital. Acta Orthop Belg. 2008;74(5):602-8.

15. Lungershausen $W$, Bach $O$, Lorenz CO. [Locking plate osteosynthesis for fractures of the proximal humerus]. Zentralbl Chir. 2003;1289(1):28-33.

16. Neer CS 2 nd. Displaced proximal humeral fractures: Part I. Classification and evaluation. J Bone Joint Surg Am. 1970;52(6):1077-89.

17. Ellman H, Kay SP. Arthroscopic subacromial descompression for chronic im- dealt with. Correct reduction and fixation of fractures of the proximal extremity of the humerus using this type of synthesis requires technical skills from the surgeon and this, in turn, implies a long learning curve. Südkamp et $a l^{(19)}$ concluded that $55 \%$ of the complications encountered were already present at the end of the surgical procedure, and related to incorrect surgical technique. In our study, this occurred in $46.7 \%$ of the complications.

\section{CONCLUSION}

The Philos ${ }^{\circledR}$ "locking plate" is a treatment option for fractures of the proximal extremity of the humerus, especially in cases of porous bones and comminutive fractures. Nevertheless, we found a complication rate of around $35.7 \%$ with this type of surgery when this osteosynthesis material was used. pingement. Two five years results. J Bone Joint Surg Br. 1991;73(3):395-8.

18. Fazal MA, Haddad FS. Philos plate fixation for displaced proximal humeral fractures. J Orthop Surg. 2009;17(1):15-8.

19. Südkamp N, Bayer J, Hepp P, Voigt C, Oestern H, Kääb M, et al. Open reduction and internal fixation of proximal humeral fractures with use of the locking proximal humerus plate. Results of a prospective, multicenter, observational study. J Bone Joint Surg Am. 2009;91(6):1320-8.

20. Owsley KC, Gorczyca JT. Displacement/screw cutout after open reduction and locked plate fixation of proximal humeral fractures. J Bone Joint Surg Am. 2008;90(2):233-40.

21. Thanasas C, Kontakis G, Angoules A, Limb D, Giannoudis P. Treatment of proximal humerus fractures with locking plates: a systematic review. J Shoulder Elbow Surg. 2009;(18):837-44

22. Kettler M, Biberthaler P, Braunstein V, Zeiler C, Kroetz M, Mutschler W. [Treatment of proximal humeral fractures with the PHILOS angular stable plate. Presentation of 225 cases of dislocated fractures]. Unfallchirurg. 2006;109(12):1032-40.

23. Gardner MJ, Weil Y, Barker JU, Kelly BT, Helfet DL, Lorich DG. The importance of medial support in locked plating of proximal humerus fractures. J Orthop Trauma. 2007;21(3):185-91.

24. Cohen M, Amaral MV, Monteiro M, Brandão BL, Motta Filho GR. Osteossíntese das fraturas da extremidade proximal do úmero com sistema de placa de ângulo fixo com parafusos bloqueados: técnica e resultados. Rev Bras Ortop. 2009;44(2):106-11.

25. Tingart MJ, Lehtinen J, Zurakowski D, Warner JJP, Apreleva M. Proximal humeral fractures: regional differences in bone mineral density of the humeral head affect the fixation strength of cancellous screws. J Shoulder Elbow Surg. 2006;15(5):620-4.

26. Rose PS, Adams CR, Torchia ME, Jacofsky DJ, Haidukewych GG, Steinmann SP. Locking plate fixation for proximal humeral fractures: initial results with a new implant. J Shoulder Elbow Surg. 2007;16(2):202-7.

27. Handschin AE, Cardell M, Contaldo C, Trentz O, Wanner GA. Functional results of angular-stable plate fixation in displaced proximal humeral fractures. Injury. 2008;39(3):306-13.

28. Monteiro GC, Ejnisman B, Andreoli CV, Pochini AC, Olympio E. Resultados do tratamento das fraturas do terço proximal do úmero com placas de bloqueio. Acta Ortop Bras. 2011;19(2):69-3.

29. Egol KA, Ong CC, Walsh M, Jazrawi LM, Tejwani NC, Zuckerman JD. Early complications in proximal humerus fractures (OTA Types 11) treated with locked plates. J Orthop Trauma. 2008;22(3):159-64.

30. Charalambous CP, Siddique I, Valluripalli K, Kovacevic M, Panose P, Srinivasan $M$, et al. Proximal humeral internal locking system (PHILOS) for the treatment of proximal humeral fractures. Arch Orthop Trauma Surg. 2007;127(3):205-10.

31. Edwards SL, Wilson NA, Zhang L, Flores S, Merk BR. Two-part surgical neck fractures of the proximal part of the humerus. A biomechanical evaluation of two fixation techniques. J Bone Joint Surg Am. 2006;88(10):2258-64. 